Trakya Eğitim Dergisi

Cilt 9, Sayı 3

Eylül 2019, 477-486

Gelis Tarihi: 14.09.2018

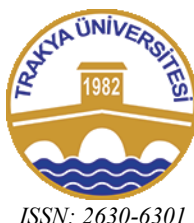

ISSN: 2630-6301
Trakya Journal of Education

Volume 9, Issue 3

September 2019, 477-486

\title{
Gereklilik, Gelişme, Süreklilik ve Teşvik Aracı Olarak Yaşamboyu Öğrenme: Metaforik Algilar ${ }^{1}$
}

\section{Lifelong Learning as a Necessity, Progress, Durableness and Incentive Tool: Metaphoric Perceptions}

\section{Gözde SEZEN-GÜLTEKİN², Duygu GÜR ERDOĞAN ${ }^{3}$}

\begin{abstract}
Öz: Bu araştırmada lisansüstü öğrencilerinin yaşam boyu öğrenme kavramına ilişkin metaforik algılarını ortaya koymayı amaçlamaktadır. Bu kapsamda, araştırma modeli nitel araştırma modellerinden fenomenoloji deseni ile tasarlanmıştır. Araştırma grubunun belirlenmesinde, amaçlı örneklem yöntemlerinden biri olan kriter örneklem tercih edilmiştir. Bu kapsamda, araştırma grubu Sakarya Üniversitesi Eğitim Bilimleri Enstitüsünde uzaktan eğitim alan yüksek lisans öğrencilerinden oluşmaktadır. Verilerin toplanması için araştırmacılar tarafından bir yarı yapılandırılmış görüşme formu geliştirilmiştir. Araştırma kapsamında, geçerlik ve güvenirliği sağlamak adına inanırlık, aktarılabilirlik, güvenilebilirlik ve onaylanabilirlik ölçütleri göz önünde bulundurularak bazı tedbirler alınmışır. Araştırma grubundan elde edilen verilerin analizinde içerik analizi yöntemi kullanılmıştır. Yüksek lisans öğrencilerinin yaşamboyu öğrenme ile ilgili toplam farklı metaforlar geliştirdiği görülmüştür. $\mathrm{Bu}$ metaforlar gerekçelerine göre incelenmiş ve sonrasında bu gerekçeler üzerinden gereklilik, gelişim, süreklilik ve teşvik şeklinde dört kategori oluşturulmuştur. Bu bağlamda, elde edilen bulgulara dayalı olarak sonuç ve tartışma belirtilmiş; ayrıca yaşamboyu öğrenmenin bu dört yönü vurgulanarak öneriler sunulmuştur.
\end{abstract}

Anahtar sözcükler: Yaşamboyu ögrrenme, metafor, lisansüstü ögrenciler, nitel araştırma

\section{Introduction}

\section{EXTENDED ABSTRACT}

This study aims to reveal the metaphorical perception of participants regarding the concept of lifelong learning. For this purpose, the metaphorical perceptions for the concept of lifelong learning of the postgraduate students having distance education master program was tried to be determined. Therefore, their views and perspectives on the concept of lifelong learning were tried to be revealed concretely.

\section{Method}

In this context, the research model was designed with phenomenology pattern which is a qualitative research model. In the determination of the study group, sampling criteria which is a purposeful sampling methods was preferred. In this regard, the study group consists of 31 postgraduate students who have distance education at Sakarya University Institute of Education Sciences. For collecting data, a semistructured interview form developed by the researchers was used. Considering credibility, transferability, dependability and confirmability criteria, some measures were taken and the methods were applied in order to ensure trustworthiness. The data obtained from the participants were analyzed through content analysis

\footnotetext{
${ }^{1} \mathrm{Bu}$ çalışma $2^{\text {nd }}$ International Conference on Lifelong Education and Leadership for All-ICLEL-16, July 21-23, 2016, Liepaja, Latvia'da özet bildiri olarak sunulmuştur.

${ }^{2}$ Dr., Sakarya Üniversitesi, Eğitim Fakültesi, Eğitim Bilimleri Bölümü, email: gsezen@sakarya.edu.tr ORCID: 0000-0002-21794466

${ }^{3}$ Dr. Öğr. Üyesi, Sakarya Üniversitesi, Eğitim Fakültesi, Eğitim Bilimleri Bölümü, email: dgur@sakarya.edu.tr ORCID: 00000002-2802-0201
} 
method. It was seen that the participants developed totally 31 different metaphors related to lifelong learning.

\section{Results and Discussion}

The findings can be summarized as following: (1) The metaphors obtained were gathered in four different categories as necessity, development, continuity and encouragement according to their rationales. When looking at these categories, it was seen that the continuity category $(f=16)$ alone accounts for $52 \%$ of all the categories. In this case, it can be said that the participants see lifelong learning as continuity. On the other hand, it was seen that the categories following the continuity category were development $(f=7)$, necessity $(f=5)$ and encouragement $(f=3)$ categories respectively. In this case, it can be said that the concept of learning of life is seen as a far more continuous and development focused action. (2) When the concept of lifelong learning was addressed under the necessity category, it was observed that there were 5 different metaphors such as water-air-soil $(\mathrm{f}=1)$, heart $(\mathrm{f}=1)$, water drinking $(\mathrm{f}=1)$, obligation $(\mathrm{f}=1)$ and jewelery ceremony $(\mathrm{f}=1)$. When the produced metaphors are analyzed in terms of their rationales, it can be said that the concept of lifelong learning is generally regarded as "a necessary act for the continuity of life". (3) When the concept of lifelong learning was addressed under the development category, it was observed that there were 7 different metaphors such as tires ( $f=1)$, the theory of evolution $(f=1)$, image $(f=1)$, sun $(f=1)$, ascension $(f=1)$, life itself $(f=1)$ and sense organs $(f=1)$. When the produced metaphors are analyzed in terms of their rationales, it can be said that the concept of lifelong learning is generally regarded as "a developer action which has a feature that increases and advances day by day". (4) When the concept of lifelong learning was addressed under the continuity category, it was observed that there were 16 different metaphors such as a rolling stone gathers no moss $(\mathrm{f}=1)$, aged wine $(\mathrm{f}=1)$, breathing $(\mathrm{f}=1)$, life cycle $(\mathrm{f}=1)$, stars $(\mathrm{f}=1)$, infinite life $(\mathrm{f}=1)$, Adam's ale $(\mathrm{f}=1)$, life $(\mathrm{f}=1)$, maze with no exit $(\mathrm{f}=1)$, bottomless well $(\mathrm{f}=1)$, water $(\mathrm{f}=1)$, infinity $(\mathrm{f}=1)$, inner life $(\mathrm{f}=1)$, reading a book many times ( $\mathrm{f}$ $=1)$, repeating $(f=1)$, readable book $(f=1)$, special hobby $(f=1)$. When the produced metaphors are analyzed in terms of their rationales, it can be said that the concept of lifelong learning is generally regarded as "an action that spreads over time and has continuity". (5) When the concept of lifelong learning was addressed under the encouragement category, it was observed that there were 3 different metaphors such as salty water $(\mathrm{f}=1)$, keeping the brain constantly active $(\mathrm{f}=1)$, theater $(\mathrm{f}=1)$. When the produced metaphors are analyzed in terms of their rationales, it can be said that the concept of lifelong learning is generally regarded as "an action which exhort and encourage a person".

This study aimed to reveal the metaphorical perception of the participants who were postgraduate students at a state university about the concept of lifelong learning. In this context, the metaphors obtained from the participants were evaluated according to their rationales. After this evaluation, four categories including requirement, development, continuity and encouragement were created. In this context, it can be said that the concept of learning of life is seen as a far more continuous and development focused action, a necessary act for the continuity of life, a developer action which has a feature that increases and advances day by day, an action that spreads over time and has continuity, an action which exhort and encourage a person. Based on these results, it is suggested that different viewpoints about the learning of life should be emerged and applied in different sampling groups in terms of giving richness to the literature by expanding this study.

\section{GİRIŞ}

Dünya çok yönlü ve oldukça hızlı bir değiş̧im içindedir. Zaman içerisinde değişimin niteliği, yönü ve kapsamı üzerine farklı bakış açıları ile farklı tanımlar yapılsa da genel olarak kabul edilen şey değişimin artarak hızlandığı ve sürekli olduğudur (Bağc1, 2011). Özellikle değişimin teknolojik, ekonomik ve eğitimsel yönü bilginin değişimini de beraberinde getirmiştir. Hızla artan bilgi bireylerin eğitim ihtiyaçlarının yönünü de değiştirerek, eğitim gereksinimlerini arttırmıştır. Bu doğrultuda değişime yetişmeye çalışan insanın eğitim tarafından yeni koşullara ve gelişmelere donanımlı hale getirilme ihtiyacı ortaya çıkmaktadır ve artık yaşam döngüsünde eğitim, sosyal bir gereklilik, bir zorunluluk olarak görülmektedir (Zgaga, 2008). Bu bağlamda değerlendirildiğinde eğitim sadece okul yaşındaki çocuklar ya da meslek sahibi olmak isteyen yetişkinlerin eğitim gereksinimleri ile sınırlı olmayıp tüm bireyler için bütün öğrenme çevrelerinde yaşam boyu devam eden bir süreç olarak ele alınmalıdır (Doğan ve Kavtelek, 2015). Çünkü yaşam boyu öğrenme hayatın belirli bir dönemine sıkıştırılmış öğrenme becerilerinin aksine sürekli ve hızlı değişen koşullara uyum sağlamak için evde, işte gibi öğrenme ortamı olabilecek her yerde ve bütün yaşam boyunca sürecek bir öğrenme sürecini ifade etmektedir (Polat ve Odabaş, 2008). Yaşam boyu 
öğrenme kişilerin yaşamları süresince elde ettikleri bilgileri, becerileri, değerleri ve anlayışları sürekli artıran ve güçlendiren, ayrıca gerçek yaşamda uygulayabilmesi için destekleyici bir süreçtir (Candy, 1994).

Yaşam boyu öğrenmenin temel dayanak noktas1, yaşam süresi boyunca öğrenenlerin gelişmesi için gerekli bilgi ve beceriler ile okul, kolej ve ya üniversitede donatmanın mümkün olmayacağıdır (Sharples, 2000). Bu nedenle insanlar bilgi ve becerilerini geliştirmek, mesleki gelişim sürecine katılmak ve sürekli gelişmek için yaşam boyu öğrenmeye ihtiyaç duyacaktır ve bu durum yaşam boyu öğrenme gerekliliğini ortaya çıkarmaktadır. Çünkü yaşam boyu öğrenme, bireyin kişiliğinde sosyal ve mesleki alanında gelişimini amaçlayan tüm yaşamı boyunca devam eden geniş bir kavramdır (Koç, 2005). Küreselleşen ve değișen dünyada eğitim; sürekli öğrenmeyi, öğrenerek bilgili olmayı, bilgiyi bilmeyi, bilgiyi uygulamayı, bilgiyi üretmeyi, bilgi ile yaşamayı sağlayan bir süreç olarak karşımıza çıkmaktadır (Çalık ve Sezgin, 2005). Bireyin üretkenliğini gelişen dünyanın ve günümüz şartlarına göre devam ettirebilmesi için, bireyin daha farkl1 ve çoklu nitelikler kazanması gerekebilir ki bu nitelik kazanma durum gerekliliği, bireyi yeni eğitim almaya zorlamaktadır (Yazar, 2012). Sürekli gelişen teknoloji ve hızla artan bilgi birikimi karşısında, eğitimin yaşam boyu devamı sağlanmalıdır (Garner, 2002).

Bir gereklilik ve süreklilik olarak karşımıza çıkan yaşam boyu öğrenme aktif ve sürekli bilgi kullanımını gerektirdiği (Berberoğlu, 2010) için yaşam boyu öğrenmeye ilişkin eğitim ortamlarında çoklu ortam yazılımlarını ve öğrenme ağlarını kullanarak bireylere bilgiye ulaşma becerisi kazandırılmalıdır (Akbaş ve Özdemir, 2002). Bilgiye ulaşmada gerçekleşen bilgi teknolojilerindeki gelişmeler ile birlikte yaşam boyu öğrenme ile ortaya çıkan bilgiye hızlı ve sürekli ulaşma ihtiyacı e-öğrenmeyi de beraberinde getirmektedir. Yaşam boyu öğrenme gereksinimi, özellikle bireylerden beklenen, bilgi ve becerilerin artmas1, değişmesi ve çeşitlenmesi ancak bireylerin yeteri kadar geleneksel eğitimden yararlanamama sonucu, teknolojilerin yayılması ile e-öğrenme biçiminde ortaya çıkan uzaktan eğitimi gerekli kılmaktadır (Aşkar, 2003). E-öğrenme, sınıf kavramını dört duvar arasından çıkartarak, dünyanın herhangi bir yerindeki bilgisayar sınıf olabilmekte ve bu durum ise özellikle yükseköğretime erişimi yükseltmektedir (Yılmaz ve Horzum, 2005). E-öğrenim, insanların evlerinden, bulundukları ortamlardan hatta ailelerinden ayrılmadan mesleki yaşamlarında ilerleme kaydedebilecekleri veya daha fazla öğrenme ve daha fazla üretken olabilmek için bilgilerini, becerilerini ve öğrenme deneyimlerini geliştirebilecekleri, teknolojik bileşenlerinden oluşan bir eğitim modeli olarak gösterilmektedir (Bonk, 2002). E-öğrenme, öğrenmeyi daha ilgi çekici olarak sunarken farklı kesimlerden bireylerin öğrenme sürecine daha fazla katılmasını sağlamada önemli bir alternatif olmasının yanı sıra özellikle çeşitli lisansüstü programların ve sertifika programlarının, "eöğrenme" ortamından sunulması gibi uygulamalar, yaşam boyu öğrenmenin önünü açmada ve çeşitli yaşam boyu öğrenme seçeneklerine yönelik ciddi imkanlar sunmaktadır (Göktaş ve Kayri, 2005; Bonk, 2002). Sonuçta yaşam boyu öğrenmenin sağlanması, gelişen mobil öğrenme teknolojileri ile birlikte bilgi teknolojisi ve e-öğrenmeye dayanmaktadır (Dinevski, 2008).

Uzaktan eğitimde öğrenen birey kendi kendine öğrenme süreci içerisinde olup öğrenmeyi yalnız başına gerçekleştirir. Bu durum öğrenen bireyin bilgilere farklı yollardan ulaşıp edinmesi ve ulaştı̆̆ bu bilgileri kendi kendine anlamlandırarak öğrenebilmesi böylece yaşam boyu öğrenme becerisi geliştirmesi demektir (Oran ve Karadeniz, 2007). Bilişim teknolojileri kullanılarak yürütülen uzaktan eğitim uygulamalarında kaydedilen ilerlemeler, uzaktan eğitimin yakın gelecekte örgün eğitime ciddi bir alternatif olacağını göstermektedir (Erturgut, 2008). Bu konuda özellikle üniversitelerin hızlı bir şekilde e-öğrenmeyi kapsayan uzaktan eğitim sistemlerine geçiş yaptığı görülmektedir. Çünkü üniversiteler esnek yapıları, yüksek uyum yetenekleri ile yüzyıllarca değişen koşullara göre gelişen, toplumun güçlü kurumlarıdır (Günay, 2007). Türkiye'de uzaktan yükseköğretim sertifika, ön lisans ve yüksek lisans boyutlarında değişik üniversitelerde internete dayalı olarak yapılmaktadır (Çukadar ve Çelik, 2003). Bu bağlamda, yaşam boyu öğrenme becerisi olan kendi kendine öğrenen birey olmanın teşvik edici yolu olarak üniversitelerde uygulanan internete dayalı uzaktan yükseköğretim lisansüstü programlarına devam eden öğrencilerin yaşam boyu öğrenme kavramına ilişkin algıları ve bakış açılarını öğrenme önemli görülmektedir. Bu amaç doğrultusunda planlanan bu çalışmada uzaktan eğitim lisansüstü programına dahil olan öğrencilerin yaşam boyu öğrenme kavramına ilişkin metaforik algıları belirlenmeye çalışılmıştır. Çünkü metaforlar, analiz edilmek istenen kavramlarının nasıl algılandığını ortaya çıkarmaya katkı sağlar (Cerit, 2008) ve böylelikle eğitimcilere iki şey arasında karşılaştırma yapmak, iki şey arasındaki benzerliklere dikkat çekmek veya bir şeyi başka bir şeyin yerine koyarak açıklamak için firsat tanırlar (Saban, 2004). Bu yolla yaşam boyu öğrenme kavramına ilişkin algıları ve bakış açıları somut olarak ortaya çıkarılmaya çalışılmıştır. 


\subsection{Araştırma Modeli}

\section{YÖNTEM}

Bu çalışma nitel araştırma yöntemi ile desenlenmiştir. Bu kapsamda, araştırmada olgubilim deseni kullanılmıştır. $\mathrm{Bu}$ desenin kullanılmasındaki amaç, aslında bize farklı görünmeyen ancak hakkında derinlemesine bir kavrayış geliştirmediğimiz durumları incelemektir (Yıldırım ve Şimşek, 2003).

\section{2. Çalışma Grubu}

Katılımcılar, amaçlı örnekleme yöntemlerinden biri olan ölçüt örnekleme kullanılarak belirlenmiştir. Pattona'a (1987) göre amaçlı örnekleme, bilgi açısından zengin durumların daha derinlemesine çalışılmasına olanak vermektedir. Bu sebeple, amaçlı örnekleme yöntemi çoğu koşulda olgu ve olayların keşfinin yapılması ve bunların izah edilmesinde faydalı olmaktadır (Glesne, 2012; Yıldırım ve Şimşek, 2003). Öte yandan ölçüt örnekleme, önceden belirlenen bazı ölçütleri taşıyan bütün durumların incelenmesidir (Yıldırım ve Şimşek, 2003). Bu hususta katılımcıların seçiminde lisansüstü eğitim görmeleri ölçüt olarak belirlenmiştir. Çünkü lisansüstü eğitim, yaşamboyu öğrenme becerilerini de içine alan ve bu becerilerin pekiştirilmesine fayda sağlayan bir süreç olarak değerlendirilebilir. Bu kapsamda Sakarya Üniversitesi Eğitim Bilimleri Enstitüsünde lisansüstü eğitim gören 36 öğrenci çalışma grubuna dahil edilmiştir. Ancak verilerin analizi sonucunda 36 katılımcıdan 5'inin vermiş olduğu cevapların metafor niteliği taşımaması ve ifade ettikleri gerekçeler ile belirttikleri metaforlar arasında tutarsızlık olmasından dolayı bu kişilere ait formlar analiz dışında bırakılmıştır. Bu sebeple analizlere, kalan 31 form üzerinden devam edilmiştir.

Tablo 1. Araştırmaya katılanlara ilişkin demografik bilgiler

\begin{tabular}{|c|c|c|c|}
\hline Değişken & Düzey & $\mathbf{N}$ & Yüzde (\%) \\
\hline \multirow{4}{*}{ Cinsiyet } & Kadın & 20 & 56 \\
\hline & Erkek & 16 & 44 \\
\hline & Boş & 0 & 0 \\
\hline & Toplam & 36 & 100 \\
\hline \multirow{5}{*}{ Yaş } & $20-30$ & 12 & 33 \\
\hline & $31-40$ & 16 & 44 \\
\hline & 41 ve üstü & 6 & 17 \\
\hline & Boş & 2 & 6 \\
\hline & Toplam & 36 & 100 \\
\hline \multirow{4}{*}{ Medeni Durum } & Evli & 26 & 72 \\
\hline & Bekar & 9 & 25 \\
\hline & Boş & 1 & 3 \\
\hline & Toplam & 36 & 100 \\
\hline \multirow{11}{*}{ Meslek } & Öğretmen & 19 & 53 \\
\hline & Müdür & 5 & 14 \\
\hline & Sağlıkçı & 5 & 14 \\
\hline & Askeri Personel & 2 & 6 \\
\hline & Diğer & 4 & 11 \\
\hline & Öğretim Görevlisi & 1 & \\
\hline & Memur & 1 & \\
\hline & İnsan Kaynakları & 1 & \\
\hline & Sosyal Yardım ve İnceleme Görevlisi & 1 & \\
\hline & Boş & 1 & 3 \\
\hline & Toplam & 36 & 100 \\
\hline \multirow{7}{*}{ Mesleki Kıdem } & $1-5$ y1l & 8 & 22 \\
\hline & $6-10$ y1l & 9 & 25 \\
\hline & $11-15$ y1l & 7 & 19 \\
\hline & $16-20$ y1l & 5 & 15 \\
\hline & 21 yıl ve üstü & 3 & 8 \\
\hline & Boş & 4 & 11 \\
\hline & Toplam & 36 & 100 \\
\hline \multirow{2}{*}{ Program Türü } & EYD & 25 & 69 \\
\hline & EPO & 11 & 31 \\
\hline
\end{tabular}




\subsection{Veri Toplama Aracı ve Verilerin Toplanması}

$\mathrm{Bu}$ araştırmada, veri toplama yöntemi olarak araştırmacılar tarafından geliştirilen açık uçlu anket formu kullanılmıştır. Uygulama öncesinde taslak form oluşturularak uzman görüşü alınmış, bu görüşlere ilişkin dönütler doğrultusunda forma son şekli verilmiştir. Bu hususta, katılımcılara ilgili form dağıtılmış ve ardından bu formun doldurulmasına yönelik bir açıklama yapılmıştır. Bu açıklamanın ardında, formların doldurulması için katılımcılara 10 dakika süre tanınmıştır. Olası bir kavram kargaşasını önlemek adına formda, metaforun ne olduğu ve nasıl bir işlevinin olduğuna ilişkin açılamalara yer verilmiştir. $\mathrm{Bu}$ kapsamda, katılımcılardan "Yaşamboyu öğrenme ............. gibidir. Çünkü ......................" ifadesinin doldurulması ve gereğinin açıklanması istenerek katılımcıların yaşamboyu öğrenmeye ilişkin algıları tespit edilmeye çalışılmıştır.

\subsection{Geçerlik ve Güvenilirlik}

Nitel araştırma biçiminde hazırlanan bu çalışmada, geçerlik ve güvenirliği sağlamak adına inanırlık, aktarılabilirlik, güvenilebilirlik ve onaylanabilirlik ölçütleri göz önünde bulundurularak bazı tedbirler alınmış ve yöntemler uygulanmıştır. İnanılırlığın sağlanması için geliştirilen form uzman görüşüne sunulmuş; katılımcılardan gelen cevaplara sadık kalınarak gerektiğinde, bu cevaplardan doğrudan alıntılar yapılmış; ayrıca elde edilen cevapların değerlendirilmesinde gözlemci üçgenlemesi yöntemi kullanılmıştır. Aktarılabilirlik, güvenilebilirlik ve objektifliğin sağlanması için amaçlı örneklem türlerinden ölçüt örnekleme yöntemi tercih edilmiş; bu hususta, çalışma grubu, başka örneklemlerle karşılaştırma yapılabilecek biçimde ayrıntılı olarak tanımlanmış ve çalışma grubu, araştırılan konuya ilk elden maruz kalan ve farklı bilim dallarında (eğitim yönetimi ve denetimi, eğitim programları) öğrenim gören lisansüstü eğitim öğrencileri işe koşularak çeşitlendirilmiştir. Yine elde edilen cevapların değerlendirilmesinde veriler araştırmacılar tarafından ayrı ayrı gözden geçirilerek araştırmacı üçgenlemesi yöntemi kullanılmıştır. Bu yolla verilerin analizinde ve yorumlanmasında geçerlik ve güvenirlik adımları sağlanmaya çalışılmıştır.

\subsection{Verilerin Analizi}

Metaforlar araştırmalarda mevcut durumu belirlemek için bir amaç ya da bir durumu tanımlamak için araç olarak kullanılmaktadır. Bu araştırmada ise elde edilen metaforlar, var olan durumu belirlemek amacıyla kullanılmıştır. Bu hususta verilerin analizinde içerik analizi kullanılmış ve orijinal formlara sadık kalınarak kategoriler oluşturulmuştur. Araştırmada katılımcılardan elde edilen veriler aşağıda verilen aşamalardan geçirilerek analiz edilmiştir: (1) metaforların belirlenerek uygun olmayanların ayıklanması, (2) gerekçelerin incelenerek metafor ve açıklaması arasında tutarsız gerekçeye sahip olanların elenmesi, (3) kalan metaforların kategorilere ayrılması. Bu aşamaların sonucunda, 36 katılımcıdan 5 'inin vermiş olduğu cevapların metafor niteliği taşımaması ve ifade ettikleri gerekçeler ile belirttikleri metaforlar arasında tutarsızlık olmasından dolayı bu kişilere ait formlar analiz dışında bırakılmıştır. Bu sebeple analizlere, kalan 31 form üzerinden devam edilmiştir.

\section{BULGULAR}

Tablo 2. Katılımcı görüșlerinden elde edilen metaforlar

\begin{tabular}{|c|c|c|}
\hline Gerekçelere Yönelik Kategoriler & $\%$ & Frekans \\
\hline $\begin{array}{l}\text { Zorunluluk } \\
\text { (Olmazsa olmaz, Su-hava-toprak, Kalp, Su içmek, Mecburiyet, Takı töreni ) }\end{array}$ & 16 & 5 \\
\hline $\begin{array}{l}\text { Gelişim } \\
\text { (Lastik, Darwin'in evrim teorisi, Resim, Güneş, Ağış, Hayatın kendi, Duyu organları) }\end{array}$ & 22 & 7 \\
\hline $\begin{array}{l}\text { Süreklilik } \\
\text { (İşleyen demirin ışıldaması, Yıllanmış şarap, Nefes almak, Hayat döngüsü, Sonsuz yaşam, Ab-1 } \\
\text { hayat, Hayat, Yıllanmış şarap, Dipsiz kuyu, Su, Sonsuzluk, Hayatın içinden, Bir kitabı defalarca } \\
\text { okumak, Tekrar tekrar okunabilecek kitap, hobi) }\end{array}$ & 52 & 16 \\
\hline
\end{tabular}


Teşvik etme

(Tuzlu su, Beynini sürekli aktif tutma, Tiyatro)

Tablo 2'de görüldüğü üzere, elde edilen metaforlar gerekçelerine göre zorunluluk, gelişim, süreklilik ve teşvik etme olmak üzere 4 ayrı kategoride toplanmıştır. Bu kategorilere göz atıldığında, süreklilik kategorisinin ( $\mathrm{f}=16)$ tek başına bütün kategorilerin \%52'sini oluşturduğu görülmektedir. Bu durumda, katılımcıların yaşamboyu öğrenmeyi özellikle süreklilik olarak gördükleri söylenebilir. Öte yandan Tablo 2'de, sürekliliği takip eden kategorileri sırasıyla gelişim ( $\mathrm{f}=7$ ), zorunluluk ( $\mathrm{f}=5)$ ve teşvik etme ( $\mathrm{f}=3$ ) olduğu görülmektedir. Bu durumda, yaşamboyu öğrenme kavramının daha ziyade süreklilik ve gelişim arz eden bir eylem olarak görüldüğü söylenebilir.

Tablo 3. Zorunluluk yönüyle yaşamboyu öğrenmeye ilişkin bilgiler

\begin{tabular}{cll}
\hline Gerekçeye Yönelik Kategori & \multicolumn{1}{c}{ Metafor } & \multicolumn{1}{c}{ Gerekçe } \\
\hline \multirow{2}{*}{ Zorunluluk } & Su-hava-toprak & Hayatı yaşamak için öğrenmek şarttır \\
& Kalp & Daima beslenmeye, gelişmeye, yenilenmeye ihtiyacı vardır \\
& Su içmek & Yaşam için olmazsa olmaz \\
& Mecburiyet & Hayatın tekamülü için sürekli gelişim şarttır \\
& Takı töreni & Ne takılırsa razı olursun \\
\hline
\end{tabular}

Tablo 3'e göre, yaşamboyu öğrenme kavramı zorunluluk kategorisi altında ele alındığında su-havatoprak $(\mathrm{f}=1)$, kalp $(\mathrm{f}=1)$, su içmek $(\mathrm{f}=1)$, mecburiyet $(\mathrm{f}=1)$ ve takı töreni $(\mathrm{f}=1)$ ") şeklinde 5 farklı metafor yer almaktadır. Üretilen metaforlar gerekçeleri açısından incelendiğinde genel olarak yaşamboyu öğrenme kavramının "hayatın devamlılığı için zorunlu bir eylem" olarak görüldüğü söylenebilir.

Tablo 4. Gelişim yönüyle yaşamboyu öğrenmeye ilişkin bilgiler

\begin{tabular}{cll}
\hline Gerekçeye Yönelik Kategori & \multicolumn{1}{c}{ Metafor } & \multicolumn{1}{c}{ Gerekçe } \\
\hline & Lastik & Çektikçe, uğraştıkça büyür \\
& Darwin'in evrim teorisi & Belli bir dönem kadar sürekli gelişme \\
& Resim & Resmin ayrıntısında yeni şeylere ulaşma \\
Gelişim & Güneş & Her gün gelişen ve artan bilginin insana yansıması \\
& Ağış (yükselmek) & Her yeni bilgi katkı sağlar \\
& Hayatın kendi & İnsan yaşadıkça öğrenir, öğretir, gelişir \\
& Duyu organları & Hisseder, yapıp yaşarız \\
\hline
\end{tabular}

Tablo 4'e göre, yaşamboyu öğrenme kavramı gelişim kategorisi altında ele alındığında lastik ( $\mathrm{f}=1$ ), evrim teorisi $(f=1)$, resim $(f=1)$, güneş $(f=1)$, ağ 1 ș $(f=1)$, hayatın kendisi $(f=1)$ ve duyu organları $(f=1)$ olmak üzere toplamda 7 farklı metafor yer almaktadır. Üretilen metaforlar gerekçeleri açısından incelendiğinde genel olarak yaşamboyu öğrenme kavramının "her geçen gün artıran ve ilerleten bir özelliğe sahip olan geliştirici bir eylem” olarak görüldüğü söylenebilir.

Tablo 5. Süreklilik yönüyle yaşamboyu öğrenmeye ilişkin bilgiler

Gerekçeye Yönelik Kategori

Süreklilik

\section{Metafor}

İşleyen demirin 1şıldaması

Yıllanmış şarap

Nefes almak

Hayat döngüsü

Yildizlar

Sonsuz yaşam

Ab-1 hayat

Hayat

Çıkışsız labirent

Dipsiz kuyu

$\mathrm{Su}$

Sonsuzluk

Hayatın içinden

Bir kitabı defalarca okumak

\section{Gerekçe}

Günümüzü, geleceğimizi aydınlatır
Zamanla olgunlaşma
İnsanlar yaşadıkları sürece öğrenme devam eder
Bebeklikten yaşlılığa her dönem yeni bilgi edinme
Sürekli devam etmesi
Her dakika öğrenme
Sonsuz yaşam isteyen insan, sonsuz öğrenmeye
mahkumdur.
İnsanla başlar, insanlar biter
Yaşam bitse de öğrenilecekler bitmez
Yaşam devam ettikçe öğreniriz
Öğrenmenin yaşı yoktur
Sürekli öğrenme
Hayatın her anı davranışlarımızda değişiklikler
yapar
Her gün, her yeni dönem bir şeyler öğrenmek




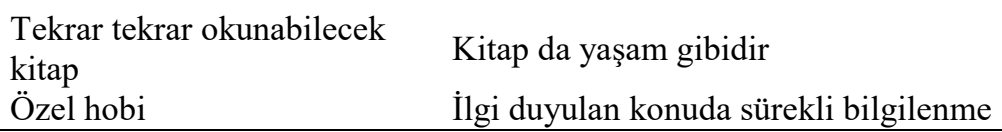

Tablo 5'e göre, yaşamboyu öğrenme kavramı gelişim kategorisi altında ele alındığında işleyen demirin 1ş1ldaması $(f=1)$, yıllanmış şarap $(f=1)$, nefes almak $(f=1)$, hayat döngüsü $(f=1)$, yıldızlar $(f=1)$, sonsuz yaşam $(\mathrm{f}=1)$, ab-1 hayat $(\mathrm{f}=1)$, hayat $(\mathrm{f}=1)$, çıkışsız labirent $(\mathrm{f}=1)$, dipsiz kuyu $(\mathrm{f}=1)$, su $(\mathrm{f}=1)$, sonsuzluk $(\mathrm{f}=1)$, hayatın içinden $(\mathrm{f}=1)$, bir kitabı defalarca okumak $(\mathrm{f}=1)$, tekrar tekrar $(\mathrm{f}=1)$, okunabilecek kitap ( $\mathrm{f}=1)$, özel hobi ( $\mathrm{f}=1)$ olmak üzere toplamda 16 farklı metafor yer almaktadır. Üretilen metaforlar gerekçeleri açısından incelendiğinde genel olarak yaşamboyu öğrenme kavramının "zamana yayılan ve süreklilik arz eden bir eylem” olarak görüldügü söylenebilir.

Tablo 6. Teşvik etme yönüyle yaşamboyu öğrenmeye ilişkin bilgiler

\begin{tabular}{cll}
\hline Gerekçeye Yönelik Kategori & Metafor & Gerekçe \\
\hline \multirow{2}{*}{ Teşvik etme } & Tuzlu su & Öğrendikçe öğrenesi gelir \\
& Beynini sürekli aktif tutma & Genç, dinamik, uyanınk kalmak \\
& Tiyatro & Farklı olaylara hoşgörü ile yaklaşma \\
\hline
\end{tabular}

Tablo 6'ya göre, yaşamboyu öğrenme kavramı gelişim kategorisi altında ele alındığında tuzlu su $(\mathrm{f}=1)$, beynini sürekli aktif tutma $(\mathrm{f}=1)$ ve tiyatro $(\mathrm{f}=1)$ olmak üzere toplamda 3 farkli metafor yer almaktadır. Üretilen metaforlar gerekçeleri açısından incelendiğinde genel olarak yaşamboyu öğrenme kavramının "kişiyi yüreklendirici, eyleme geçmede teşvik edici bir eylem" olarak görüldüğü söylenebilir.

\section{SONUÇ, TARTIŞMA ve ÖNERILER}

Elde edilen metaforlar gerekçelerine göre zorunluluk, gelişim, süreklilik ve teşvik etme olmak üzere dört ayrı kategoride toplanmıştır. Bu kategorilere göz atıldığında, süreklilik kategorisinin tek başına bütün kategorilerin \%52'sini oluş̧urduğu görülmektedir. Bu durumda, katılımcıların yaşamboyu öğrenmeyi özellikle süreklilik olarak gördükleri söylenebilir. Öte yandan, sürekliliği takip eden kategorileri sırasıyla gelişim, zorunluluk ve teşvik etme olduğu görülmektedir. Bu durumda, yaşamboyu öğrenme kavramının daha ziyade süreklilik ve gelişim arz eden bir eylem olarak görüldüğü söylenebilir. WILL (World Initiative on Lifelong Learning) (1994) raporunda yer alan yaşam boyu öğrenmeye ilişkin "Bireyleri yaşamları boyunca ihtiyaç duyacakları tüm bilgi, değer, beceri ve anlayışları edinme ve onları tüm rollerde, koşullarda ve ortamlarda güven, yaratıcılık ve zevkle uygulamalarını teşvik eden ve güçlendiren sürekli destekleyici bir süreçtir." şeklindeki tanım yaşam boyu öğrenmenin gelişimi teşvik eden bir yol ve süreklilik olarak görülmesini destekler niteliktedir. Ayrıca Ilgaz ve Eskici (2018) tarafindan yapılan çalışmada da yaşam boyu öğrenme için temel yeterlilikleri ile başarı ihtiyacı arasında bulunan anlamlı ilişki yaşam boyu öğrenmenin birey için gerekliliğini destekler niteliktedir.

Yaşamboyu öğrenme kavramı zorunluluk kategorisi altında ele alındığında su-hava-toprak, kalp su içmek, mecburiyet ve takı töreni olmak üzere 5 farklı metafor yer almaktadır. Üretilen metaforlar gerekçe açısından incelendiğinde genel olarak yaşamboyu öğrenme kavramının "hayatın devamlılığı için zorunlu bir eylem" olarak görüldüğü söylenebilir. Miser (2002) tarafından da ifade edildiği gibi küreselleşme ile birlikte insanlığg ve toplumun değişmeyi anlaması, ona uyum sağlaması, onun negatif etkilerinden korunması için bilgi, tarih sahnesinin hiçbir evresinde olmadığ gelen bilgi hızlı ve sürekli olarak değişmektedir. Bu durum da eğitimin insanları olabilecek yeni koşullara ve bilgiye hazırlıklı olmalarını sağlamaya yönelik olması gerekmekte ve eğitimin yaşam boyu, kesintisiz, sürekli araştırmalar süreci olarak yaşanmasını zorunlu kılmaktadır (Kahraman, 2016). Bu durum ise yaşam boyu eğitimi hayatın devamlılığı için zorunlu bir eylem olarak görülmesini açıklar niteliktedir.

Yaşamboyu öğrenme kavramı gelişim kategorisi altında ele alındığında lastik, evrim teorisi, resim, güneş, ağış, hayatın kendisi ve duyu organları olmak üzere toplamda yedi farklı metafor yer almaktadır. Üretilen metaforlar gerekçeleri açısından incelendiğinde genel olarak yaşamboyu öğrenme kavramının "her geçen gün artıran ve ilerleten bir özelliğe sahip olan geliştirici bir eylem" olarak görüldüğü söylenebilir. Sonuçta Kuzu, Demir ve Canpolat (2015) tarafindan da belirtildiği üzere yaşam boyu öğrenme, bireyin hayatı boyunca (beşikten mezara) yaptığı kişisel, sosyo-ekonomik ve mesleki gelişimini artırıcı anlamlı etkinliklerin tümünü kapsar. 
Yaşamboyu öğrenme kavramı süreklilik kategorisi altında ele alındığında işleyen demirin 1şıldaması, yıllanmış şarap, nefes almak, hayat döngüsü, yıldızlar, sonsuz yaşam, ab-1 hayat, hayat, çıkışsız labirent, dipsiz kuyu, su, sonsuzluk, hayatın içinden, bir kitabı defalarca okumak, tekrar tekrar, okunabilecek kitap, özel hobi olmak üzere toplamda 16 farklı metafor yer almaktadır. Üretilen metaforlar gerekçeleri açısından incelendiğinde genel olarak yaşamboyu öğrenme kavramının "zamana yayılan ve süreklilik arz eden bir eylem" olarak görüldüğü söylenebilir. Bu bulgu yaşam boyu öğrenmenin temel ifadesi olan "beşikten mezara" kavramı ile net bir şekilde uyuşmaktadır.

Yaşamboyu öğrenme kavramı teşvik etme kategorisi altında ele alındığında tuzlu su, beynini sürekli aktif tutma ve tiyatro olmak üzere toplamda üç farklı metafor yer almaktadır. Üretilen metaforlar gerekçeleri açısından incelendiğinde genel olarak yaşamboyu öğrenme kavramının "kişiyi yüreklendirici, eyleme geçmede teşvik edici bir eylem" olarak görüldüğü söylenebilir.

Elde edilen bulgular 1şığında genel olarak yaşam boyu öğrenmenin zamana yayılan ve süreklilik gerektiren böylece gelişimi sağlayan ve bireyi ilerleten, kişiyi yüreklendiren ve teşvik eden zorunlu bir eylem olarak görüldüğünü söyleyebiliriz. Yaşam boyu öğrenmenin değişen dünyada zorunlu bir eylem olarak görülmesi eğitim programlarımızda yaşam boyu öğrenme kavramının yer almasını kaçınılmaz hale getirmiştir. Özellikle ilkokuldan itibaren tüm eğitim kademelerinde yaşam boyu öğrenmenin kazandırılmasına yer verilmesi gerektiği ön görülmektedir. Bu konuda yapılan bu çalışma genişletilerek yaşamboyu öğrenme konusuna ilişkin farklı bakış açılarının ortaya çıkması ve alanyazına zenginlik kazandırması açısından farklı örneklem gruplarında uygulanması önerilebilir. 


\section{KAYNAKLAR}

Akbaş, O, ve Özdemir, S.M. (2002). Avrupa Birliğinde Yaşam Boyu Öğrenme. Milli Ĕgitim Dergisi, Say1 155-156.

Aşkar, P. (2003). Uzaktan Eğitimde Temel Yaklaşımlar ve Uzaktan Eğitimde Öğrenci (Katılımc1) Olmak. (Editör: Ali Tahran). Uzaktan Eğitim Teknolojileri ve TCMB'de Teknoloji Destekli Bilgisayar Eğitimi Konferansı, 31 Ekim 2001. Ankara: TCMB. 3-40.

Bağcı, E. (2011). Avrupa Birliği'ne Üyelik Sürecinde Türkiye'de Yaşam Boyu Eğitim Politikaları. Ondokuz Mayls Üniversitesi Eğitim Fakültesi Dergisi, 30(2), 139-173.

Berberoğlu, B (2010). Yaşam Boyu Öğrenme İle Bilgi Ve İletişim Teknolojileri Açısından Türkiye'nin Avrupa Birliği’ndeki Konumu. Bilgi Ekonomisi ve Yönetimi Dergisi , V(II), 113-126

Bonk, C. J. (2002) Online training in an online world. [Çevrimiçi] Elektronik Adres:http://www.PublicationShare.com [10.06.2018].

Cerit, Y. (2008). Öğretmen kavramı ile ilgili metaforlara ilişkin öğrenci, öğretmen ve yöneticilerin Görüşleri. Türk Eğitim Bilimleri Dergisi, 6(4), 693-712.

Çalık, T. ve Sezgin, F. (2005). Küreselleşme, Bilgi Toplumu ve Eğitim. Kastamonu Eğitim Dergisi, 13 (1). 55-66.

Çukadar, S., ve Çelik, S. (2003). İnternete Dayalı Uzaktan Öğretim Ve Üniversite Kütüphaneleri. Doğus Üniversitesi Dergisi, 4 (1), 31-42.

Dinevski, D. (2008). Open educational resources and lifelong learning. Proceedings of the ITI 2008 30th Int. Conf. on Information Technology Interfaces, June 23-26, 2008, Cavtat, Croatia

Doğan, S ve Kavtelek, C (2015). Hayat Boyu Öğrenme Kurum Yöneticilerinin Hayat Boyu Öğrenme Kavramına İlişkin Görüşleri: Hayat Boyu Öğrenme için Bir Metafor Analizi. Yükseköğretim ve Bilim Dergisi, 5(3), 292303.

Erturgut, R. (2008). İnternet Temelli Uzaktan Eğitimin Örgütsel, Sosyal, Pedagojik ve Teknolojik Bileşenleri. Bilişim Teknolojileri Dergisi, 1(2), 79-85.

Garner, L. H. (2002). Education for the Twenty-first Century: Leadership for Globalization. Iowa: Second Korea-U.S. Forum.

Glesne, C. (2012). Nitel Araştırmaya Giriş (3. Baskı). (Çev.) Ali Ersoy ve Pelin Yalçınoğlu. Ankara: Anı Yayıncılık.

Gökdaş, İ., \& Kayri, Ö. G. M. (2005). E-öğrenme ve Türkiye açısından sorunlar, çözüm önerileri. Yüzüncü Yıl Üniversitesi Eğitim Fakültesi Dergisi, 2(2), 1-20.

Günay, D.(2007). Yirmibirinci Yüzyılda Üniversite, İçinde Değişim Çağında Yükseköğretim (Editör: Çoşkun C. Aktan). İzmir: Yaşar Üniversitesi Yayını, 77-88.

Ilgaz, G. ve Eskici, M. (2018). Examination of teacher candidates' lifelong learning competence and basic motivation resources as parts of sustainability. Sustainability, 11 (23), 2-20. doi:10.3390/su11010023.

Kahraman, A (2016). Organizasyon gelişimi ve mesleki yetkinlikte yaşam boyu eğitimin etkisi. Denetişim, (7), 7890. Retrieved from http://dergipark.gov.tr/denetisim/issue/22497/240534

Koç, G. (2005). Yaşamboyu Öğrenme. İçinde: Eğitimde Yeni Yönelimler (Editör: Özcan Demirel). Ankara: Pegem A Yayınları.

Kuzu, S., Demir, S. ve Canpolat, M. (2015). Öğretmen adaylarının yaşam boyu öğrenme eğilimlerinin bazı değişkenler açısından değerlendirilmesi. Eğitimde Kuram ve Uygulama, 11(4), 1089-1105.

Miser, R. (2002). Küreselleşen dünyada yetişkin eğitimi. Ankara Üniversitesi Eğitim Bilimleri Fakültesi Dergisi, 35 $(1-2), 55-60$

Oran, M.K. ve Karadeniz, Ş. (2007). İnternet Tabanlı Uzaktan Eğitimde Mobil Öğrenmenin Rolü. Akademik Bilişim'07 - IX. Akademik Bilişim Konferansı Bildirileri 31 Ocak - 2 Şubat 2007 Dumlupınar Üniversitesi, Kütahya.

Polat, C. ve Odabaş, H. (2008). Bilgi Toplumunda Yaşam Boyu Öğrenmenin Anahtarı: Bilgi Okuryazarlı̆̆ı., İçinde: Küreselleşme, Demokratikleşme ve Türkiye Uluslararası Sempozyumu Bildiri Kitabı, Antalya (Turkey), 2730 March 2008.

Saban, A. (2004). Giriş düzeyindeki sinif öğretmeni adaylarinin "öğretmen” kavramina ilişkin ileri sürdükleri metaforlar. Türk Ĕgitim Bilimleri Dergisi, 2(2), 131-155. 
Gereklilik, Gelişme, Süreklilikve Teşvik Aracı Olarak Yaşamboyu Öğrenme...

Sharples, M (2000). The design of personal mobile technologies for lifelong learning. Computers \& Education, 34, 177-193.

WILL (World Initiative on Lifelong Learning) (1994). (An action agenda for lifelong learning for the 21st Century. Final Report from the First Global Conference on Lifelong Learning, Rome, 30 November-2 December 1994. Brussels, WILL.

Yazar, T. (2012). Yetişkin Eğitiminde Hedef Kitle. Dicle Üniversitesi Sosyal Bilimler Enstitüsü Dergisi 4(7), 21-30.

Yıldırım, A. ve Şimşek, H. (2003). Sosyal Bilimlerde Nitel Araştırma Yöntemleri (3. Baskı). Ankara: Seçkin Yayıncilik.

Yılmaz, K ve Horzum,M.B (2005). Küreselleşme, Bilgi Teknolojileri ve Üniversite. Inönü Üniversitesi Eğitim Fakültesi Dergisi, 6(10), 103-121.

Zgaga, P. (2008). Reconsidering Education for All from a Lifelong Education Perspective. Right to Education Policies and Perspectives. Türk Ĕ̈itim Derneği, 165-180. 